\title{
Cadeia de Criação e Comercialização do Cavalo Crioulo no Rio Grande do Sul
}

\author{
Bruna Pacheco da Silva* \\ Claudio Vinicius Silva Farias ${ }^{* * *}$
}

\begin{abstract}
Resumo
Este trabalho possui como objetivo analisar a cadeia de criação e comercialização do Cavalo Crioulo no Rio Grande do Sul, tendo em vista sua importância econômica e sua tradição na atividade produtiva do estado, participando, inclusive, do imaginário da região do pampa. A pesquisa está fundamentada no estudo sobre os Sistemas Agroindustriais, a Coordenação e Estruturação de Cadeias, à luz da Nova Economia Institucional. A coleta de dados foi realizada através de análise documental, de análise de dados secundários e de entrevistas em profundidade com agentes da cadeia, se caracterizando em um estudo exploratório de abordagem qualitativa. Foi realizada uma análise histórica do mercado de Cavalos Crioulos e apresentada uma proposta de estrutura da cadeia analisada, seus elos (agentes da cadeia) e como estes se relacionam.
\end{abstract}

Palavras-chave: Cavalo Crioulo. Coordenação e Estruturação de Cadeias. Nova Economia Institucional. Sistemas Agroindustriais.

* Tecnóloga em Processos Gerenciais. Professora Substituta do Instituto Federal do Rio Grande do Sul (IFRS) - Campus Porto Alegre. E-mail: bruna_pacheco_silva@hotmail.com

** Doutor em Desenvolvimento Rural (PGDR/Ufrgs). Professor do Instituto Federal do Rio Grande do Sul (IFRS) - Campus Porto Alegre. E-mail: claudio.farias@poa.ifrs.edu.br

http://dx.doi.org/10.5335/rtee.v23i48.7360

Submissão: 06/05/2016. Aceite: 16/02/2017. 


\section{Introdução}

Existe uma diversidade de raças de cavalos. Dentre elas, algumas das mais conhecidas no Brasil são o cavalo árabe, o puro sangue, o puro sangue inglês, o manga-larga, o manga-larga marchador, o quarto de milha e o cavalo crioulo. Dessas raças, a que possui maior destaque e tradição na criação, sobretudo nos países mais meridionais da América do Sul, é a raça de cavalos crioulos.

A raça crioula, de acordo com a Associação Brasileira de Criadores de Cavalos Crioulos (ABCCC, [201-?]), é oriunda de um conjunto de cavalos trazidos da península ibérica no século XVI, durante o período de colonização da América do Sul. Sua origem genética surgiu na população equina da península ibérica do século $\mathrm{XV}$, e, apesar de haver várias raças sendo criadas naquele local durante aquele período, acredita-se que o cavalo crioulo é originário de duas delas: o cavalo Andaluz e o Jacas. Essas duas raças eram conhecidas como raças guerreiras, resistentes e valentes.

Segundo informações da ABCCC em suas publicações oficiais, acredita-se que os primeiros exemplares de cavalos crioulos chegaram ao continente americano em 1493, quando Cristóvão Colombo desembarcou na Ilha de São Domingos. A partir do século XVII, muitos cavalos que vieram junto com as embarcações, principalmente espanholas, perderam-se pelo continente e, por muitos anos, foram criados livres. Foi neste período que se iniciou a raça crioula, a partir de múltiplos cruzamentos entre os cavalos selvagens.

Esses cavalos espalharam-se por diversos países de toda América. Contudo, os Cavalos Crioulos, da forma como são conhecidos hoje, ficaram concentrados, principalmente, na América do Sul, mais especificamente nos seguintes países: Argentina, Uruguai, Chile, Paraguai e o sul do Brasil. Durante quatro séculos o cavalo crioulo passou por um processo de seleção natural, em que apenas os mais fortes, resistentes e adaptados a esta nova região sobreviveram. Ou seja, a raça crioula foi moldada a partir da exposição a diversos predadores, altas variações de temperaturas, escassez de comida e água e outras dificuldades, que fizeram com que os espécimes dessa raça se fortalecessem. Apenas em meados do século XIX, os fazendeiros da região sul da América perceberam a importância e a qualidade dos cavalos crioulos e passaram a criar esses animais. A raça ganhou reconhecimento mundial a partir do século XX e começou a ser preservada desde então. Além disso, conquistou valor econômico e de comercialização ao longo dos anos, possuindo uma cadeia de criação e de comercialização complexa.

Teoria e Evidência Econômica - Ano 23, n. 48, p. 63-91, jan./jun. 2017 
Ao longo dos anos, o Cavalo Crioulo é criado visando não apenas à lida campeira, mas também a provas e competições, existindo diversos elementos, ligados à criação, à genética e às suas conquistas, que agregam valor ao animal. Dessa forma, com o passar dos anos, o valor de comercialização dos animais teve uma tendência de crescimento. Esse fato pode ser observado pela evolução recente das vendas: o mercado de cavalos crioulos teve um aumento de $\mathrm{R} \$ 100$ milhões em vendas, no período entre 2002/2012. Além disso, é importante considerar que nos últimos dez anos o valor envolvido em negociações passou de $\mathrm{R} \$ 12$ milhões em 2002, para $\mathrm{R} \$ 112$ milhões em 2012, segundo a ABCCC. Pelos dados apresentados, percebe-se que o mercado de cavalos crioulos está em crescimento, inclusive em relação ao seu grau de importância econômica.

$\mathrm{O}$ presente artigo pretende analisar a estrutura da cadeia de criação e de comercialização dos cavalos crioulos no estado do Rio Grande do Sul. Para atender a esse objetivo foram realizados, além de levantamentos bibliográficos, análises documentais e de dados secundários e entrevistas em profundidade. As entrevistas aconteceram com representantes dos diferentes elos da cadeia de criação e de comercialização, incluindo proprietários de cabanhas e representantes da ABCCC e de outras organizações. Sob o ponto de vista teórico, o estudo foi elaborado sob o referencial dos Sistemas Agroindustriais (SAGs). De forma complementar, utilizou-se a abordagem conceitual da Nova Economia Institucional (NEI), para suportar as análises sobre a coordenação e a estruturação de cadeia.

\section{Referencial teórico}

$\mathrm{Na}$ presente seção, será realizada uma revisão de literatura sobre o assunto que servirá de base para o estudo. Inicialmente, será feita uma abordagem conceitual sobre os Sistemas Agroindustriais (SAGs). Após, serão analisados os conceitos sobre a coordenação e a estrutura de cadeias, que irão auxiliar na análise da estrutura da cadeia de criação e de comercialização proposta. Finalmente, será realizada uma revisão conceitual sobre a Nova Economia Institucional (NEI).

\subsection{Sistemas Agroindustriais (SAGs)}

Os sistemas agroindustriais, segundo Saab, Neves e Claudio (2009), são um recorte feito em um determinado produto dentro do agribusiness ou agronegócio, em que este inclui todas as fases, desde a produção de insumos até o consumidor

Teoria e Evidência Econômica - Ano 23, n. 48, p. 63-91, jan./jun. 2017 
final. Zylbersztajn (2000) é um dos principais autores nacionais a abordar questões relacionadas ao Sistema Agroindustrial, definido como SAG. Para o autor, as relações verticais ao longo da cadeia de produção devem servir de balizadores para a formulação tanto de estratégias empresariais quanto da formulação de políticas públicas (ZYLBERSZTAJN, 2000).

A comercialização de um produto é um dos itens que integram a cadeia de produção agroindustrial, segundo Dias (2000). Dessa forma, a cadeia de criação e de comercialização do cavalo crioulo está localizada à jusante, ou seja, após a produção. Deve-se considerar que a criação de cavalos não passa por um processo de industrialização ou de produção, não sendo adequado, neste caso, considerar a matéria-prima e processos industriais, pois esses não se aplicam, visto que os cavalos passam por um processo de criação. Por este motivo, o processo de criação e de comercialização é bastante complexo, conforme será analisado no decorrer do trabalho.

Para Farina, "sistemas agroindustriais são definidos como nexos de contratos que viabilizam as estratégias adotadas pelos diferentes agentes econômicos envolvidos nas várias dimensões do agronegócio" (1999, p. 1). Dessa forma, compreende-se que os nexos contratuais são um dos fatores que vão garantir a competitividade dos integrantes de determinado sistema agroindustrial. Farina (1999) compreende ainda que a competitividade é uma forma de mensurar o desempenho das firmas individuais. Contudo, esse desempenho individual é o que vai garantir o desempenho obtido pelo sistema como um todo, e não apenas de forma particular, ou seja, obtida não apenas por uma organização integrante de um sistema agroindustrial.

Os diferentes agentes econômicos, citados por Farina (1999), podem ser observados na Figura 1 a seguir, assim como sua inter-relação: 
Figura 1 - Agentes econômicos e sua inter-relação

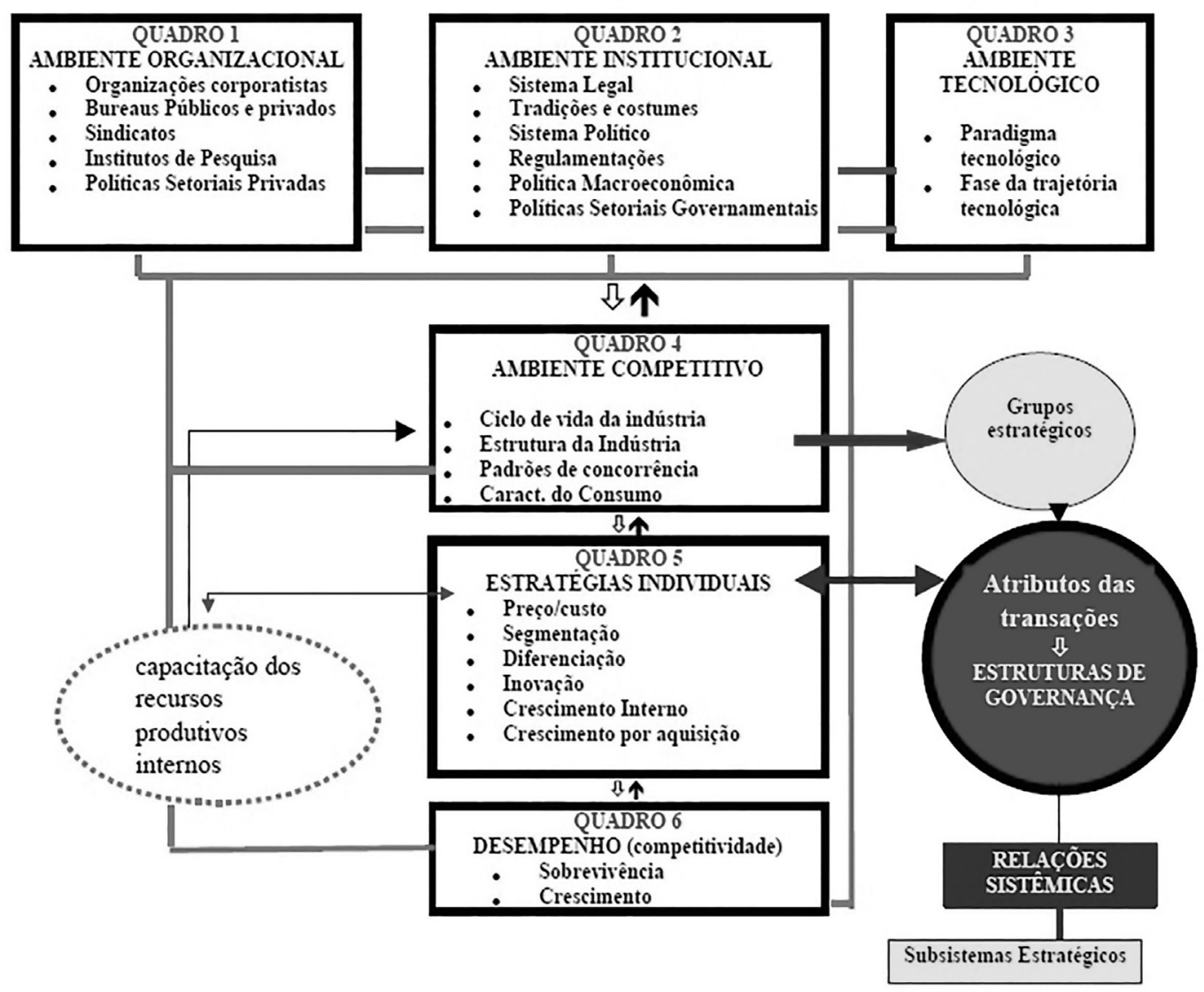

Fonte: Farina (1999, p. 10).

De acordo com Fischmann (1999), uma possível conceituação de desempenho no âmbito das organizações é a capacidade da empresa de atingir seus objetivos através da implementação de estratégias adotadas dentro do seu processo de planejamento. Dessa forma, ao considerarmos que as empresas estejam atingindo os seus objetivos estratégicos previamente determinados, aumentam-se as chances de que o Sistema Agroindustrial também atinja. Nesse caso, ao considerarmos o SAG dos cavalos crioulos, no momento em que as cabanhas, ou seja, os locais onde se criam os cavalos e também se comercializam os animais, obtém um bom desempenho, o SAG, como um todo, possui maior probabilidade de obter um bom desempenho. 
Segundo Zylbersztajn (1995), o estudo de Sistemas Agroindustriais tem ampla aplicação, indo desde o desenho de políticas públicas até a coordenação de organizações e de estratégias corporativas. Contudo, os Sistemas Agroindustriais possuem diferentes visões, ainda que em certa medida sejam complementares. As principais são o Sistema de Commodities (CSA) e o Conceito de Cadeia (Filière).

Segundo Zylbersztajn (1995), o sistema de Commodities (CSA) foi desenvolvido por David Goldberg em 1957, sendo um sistema que considera todos os atores envolvidos com a produção, o processamento e a distribuição de um produto. Tal sistema inclui o mercado de insumos agrícolas, a produção agrícola, as operações de estocagem, o processamento, o atacado e o varejo, demarcando um fluxo que vai dos insumos até o consumidor final. Esse sistema inclui ainda as organizações governamentais, os mercados futuros e as associações de comércio. Além disso, também é abordada por Zylbersztajn (1995) a questão contratual, pois se considera um importante mecanismo de coordenação de um CSA.

O conceito de Cadeia (Filière) é outra visão dos sistemas agroindustriais, oriunda da escola econômica francesa. O conceito, segundo Zylbersztajn (2000), está relacionado com uma sequência de atividades que vai transformar uma commodity em um produto que vai estar pronto para o consumidor final. Além disso, o autor considera que o sistema de cadeias (filières) possui o foco principalmente na distribuição do produto, e não no preço do produto, no que tange à coordenação da cadeia. Para Batalha (1999), o conceito de filière identifica-se com o conceito de cadeia de produção agroindustrial, uma vez que os dois conceitos consideram que o produto passará por várias etapas até chegar ao consumidor final.

O Sistema de Commodities (CSA) e o conceito de Cadeia (Filière), apesar de suas diferenças, possuem como semelhança o fato de estarem diretamente relacionados à estratégia empresarial. De acordo com Zylbersztajn (2000), o CSA é mais voltado para as ações estratégicas das organizações, e o conceito de cadeia (filière) está mais direcionado para questões estratégicas voltadas para ações governamentais.

\subsection{Coordenação e Estruturação de Cadeias}

Pode-se compreender como cadeia uma sucessão de elos, ligados uns aos outros, de forma sequencial. A coordenação e a estruturação desses elos, ou seja, a forma como estão dispostos e organizados, bem como a maneira como se relacionam, irá definir o funcionamento de determinada cadeia. Além disso, deve ser considerado todo o ambiente institucional relacionado à cadeia. 
As cadeias são formadas, além das transações econômicas, por relações técnicas, econômicas, sociais e políticas, sendo o grau de comprometimento entre seus componentes o que vai determinar sua estrutura e coordenação (BEGNIS; ESTIVALETE; PEDROZO, 2007). Além disso, é importante considerar, conforme Azevedo (2000), que a coordenação é uma construção dos agentes econômicos de uma cadeia, não sendo uma característica intrínseca aos sistemas produtivos. Ou seja, nem todo sistema produtivo surgirá com uma coordenação, visto que ela deve ser desenvolvida em conjunto pelos elos da cadeia.

Para Longhi e Medeiros (2003), o processo de coordenação de uma cadeia precisa gerar incentivos e controles para que se reduzam os custos de transação. Além disso, os autores compreendem que a competitividade dinâmica das cadeias agrícolas vai depender não exclusivamente, mas de maneira importante, de uma coordenação eficiente.

Segundo Farina, é

[...] essa coordenação que permite à empresa receber, processar, difundir e utilizar informações de modo a definir e viabilizar estratégias competitivas, reagir a mudanças no meio ambiente ou aproveitar oportunidades de lucro (1999, p. 04).

Dessa forma, considerando uma cadeia ou um sistema, quanto mais apropriada for a coordenação entre os componentes de um determinado sistema, menores serão os custos de cada um de seus determinados integrantes, ou seja, dos elos da cadeia. Farina (1999), assim como Azevedo (2000), também considera que a coordenação não desponta juntamente com o surgimento do sistema, mas que ela é fruto de uma construção dos agentes econômicos.

Ainda é importante considerar os problemas de coordenação das cadeias. De acordo com Farina (1999), para que possam ser identificados os problemas de coordenação, é necessário confrontar a estrutura de governança existente com a estrutura de governança esperada. A autora considera que a estrutura de governança esperada é aquela que irá promover a cadeia. Contudo, quando são identificados problemas no confronto entre o existente e o esperado, são necessárias ações públicas ou privadas, visando à resolução do problema de coordenação ou de governança que é verificado.

Segundo Fiani (2002), a estrutura de governança é a estrutura institucional na qual a transação é realizada, ou seja, é o conjunto de instituições e de agentes que vão garantir a execução e a realização da transação. Além disso, o autor classifica, de acordo com a teoria dos custos de transação, os tipos de governança e como as mesmas se relacionam. Existe a governança pelo mercado, a governança 
trilateral e a governança específica de transação. A primeira é aquela que é adotada em transações não específicas e possui maior eficácia nas transações recursivas. Nesse tipo de transação, as partes podem consultar a sua experiência na avaliação de uma transação, dessa forma, não é necessário esforço para amparar a relação.

Ainda segundo Fiani (2002), a governança trilateral, por sua vez, necessita da avaliação de uma terceira parte antes da realização da transação, tanto na sua avaliação quanto na solução de eventuais litígios. Esse tipo de governança é mais indicado para transações ocasionais, podendo ser esses de caráter misto ou específico.

Já a governança específica de transação, de acordo com Fiani (2002), está relacionada ao fato de que não há uma padronização dos ativos transacionais, gerando um aumento no risco da transação e na possibilidade de surgir conflitos com maior dificuldade de solução. A partir dessa governança, podem surgir dois tipos de estrutura, sendo eles um contrato de relação ou uma estrutura unificada e hierarquizada. A primeira refere-se a um contrato em que as partes preservam sua autonomia e a segunda refere-se a uma empresa, ou seja, uma estrutura, que é unificada e hierarquizada. Nesse caso, a possibilidade de escolha dessa estrutura é diretamente proporcional ao caráter idiossincrático do investimento, ou seja, a peculiaridade de cada investimento.

Para Zylbersztajn (1995), os sistemas de agrobusiness têm que ser coordenados para que o consumidor final tenha sua necessidade suprida, através da ação de distintos mecanismos. A coordenação de sistemas de agribusiness é definida como o resultado da ação de distintos mecanismos que permitem suprir as necessidades dos consumidores finais. Devido à amplitude dessa definição, o autor não considera como único mecanismo o preço, pois há diversos mecanismos contratuais e aspectos institucionais que dão suporte tanto ao funcionamento quanto à coordenação do sistema como um todo.

Além disso, as estratégias competitivas de uma cadeia dependem de estruturas de governança adequadas para que possam ser bem sucedidas (FARINA, 1999). Outro fator importante para que a coordenação seja mais eficiente, segundo Hayes et al. (2008), é a troca de informações entre os elos da cadeia, pois a coordenação necessita de comunicação, principalmente nas integrações verticais, para que seja mais eficiente.

Segundo Azevedo (2000), um sistema agroindustrial pode ter sua eficiência e sua competitividade diretamente ligadas ao comportamento dos participantes do sistema, permitindo que se tenha uma coordenação de suas ações mais apurada do que a que seria obtida por meio do uso da coordenação via sistema de preços.

Teoria e Evidência Econômica - Ano 23, n. 48, p. 63-91, jan./jun. 2017 
É importante considerar, a priori, que um conjunto de cadeias não restringe sua coordenação apenas ao sistema de preços, utilizando outros elementos, tais como fatores de qualidade de produtos, prazos de entrega, exclusividade na comercialização etc.

Ainda, conforme Farina (1999), outro fator que influencia na eficácia relativa das estruturas de governança são os graus de complexidade e de incerteza. Dessa forma, identificar os motivos que levam esse mercado á ter esse grau de complexidade e de incerteza pode colaborar na escolha mais adequada de uma estrutura de governança e, assim, minimizar os riscos causados por esses fatores.

\subsection{Nova Economia Institucional}

Os estudos sobre a Nova Economia Institucional (NEI) ganharam força a partir da década de 1960 no meio acadêmico. Os principais autores que deram início aos estudos foram Ronald Coase, Oliver Williamson e Douglass North. Para estes, as instituições, ao se constituírem em mecanismos de ação coletiva, teriam como principal objetivo aumentar a eficiência e reduzir os conflitos (CONCEIÇÃO, 2002).

No que tange ao conceito de instituições, é importante considerar o conceito de North (1994), de que as instituições são restrições, inventadas pelos homens, que estruturam as relações humanas. Elas são feitas de restrições formais (regras, leis, constituições, entre outros), restrições informais (normas de comportamento, convenções, códigos de conduta autoimpostos, entre outros) e de suas características de aplicação (enforcement).

Segundo Aguilar Filho (2009), as instituições existem em decorrência das incertezas próprias do mundo e dos elevados custos de transação. Essas instituições são as que irão coordenar as ações coletivas e que vão garantir a estabilidade necessária para o intercâmbio humano.

A NEI procura identificar qual é a melhor forma de organização das transações econômicas, cuja configuração altera as condições iniciais para alocação de recursos (FARINA, 1999). Além disso, considera-se que uma evolução institucional pode ser mais relevante para o desenvolvimento econômico do que os avanços tecnológicos (GALA, 2003).

É importante considerar ainda que, conforme Arend, Cario e Enderle (2012), os agentes da mudança institucional seriam aqueles que possuem processo decisório nas organizações, sejam empresários políticos ou econômicos, e as fontes dessas mudanças são as oportunidades percebidas por estes empresários.

No entanto, é importante diferenciar oportunidades e oportunismo, pois

Teoria e Evidência Econômica - Ano 23, n. 48, p. 63-91, jan./jun. 2017 
[...] mesmo em cadeias com elevado grau de coordenação, e nas quais existe um elevado nível de comprometimento entre os seus componentes, o auto-interesse dos agentes pode levar à sua desarticulação. Isto ocorre porque estes estão sujeitos ao oportunismo, que destrói a confiança e que é um dos pilares que sustenta a base dos relacionamentos, tanto entre indivíduos como entre organizações (BEGNIS; ESTIVALETE; PEDROZO, 2007, p. 311).

Dessa forma, é importante que os agentes da mudança institucional não sejam influenciados por processos oportunistas, para que não se coloque em risco a eficiência de determinada organização, instituição ou, até mesmo, de toda a cadeia. Para Azevedo (2000), três elementos são importantes no âmbito rural, no que tange ao ambiente institucional. São eles as regras formais, as restrições informais e os direitos de propriedade, que não se aplicam diretamente à cadeia em estudo. De acordo com o autor, as regras formais são uma das mais evidentes instituições.

Contudo, as regras não possuem importância apenas pelo seu desempenho, mas pelo modo como os agentes percebem o quão estáveis são essas regras e pelos eventuais conflitos entre elas e as demais regras informais que são estabelecidas, ou seja, a credibilidade que essas regras formais possuem, sendo esse um fator que pode afetar o desempenho econômico (AZEVEDO, 2000).

Além disso, é importante considerar a colocação do autor sobre as restrições informais, que também são instituições e que possuem tanta influência sobre o comportamento humano e sobre as organizações quanto às regras formais. Porém, essas não são explícitas como as regras formais, consistindo, de maneira geral, de valores, tabus, costumes, religiões, códigos de ética, laços étnicos e familiares, que, conforme Azevedo (2000), representam um importante papel econômico de restringir o comportamento dos agentes.

Ainda, Aguilar Filho (2009) considera que, mesmo que as regras formais possam ser alteradas no âmbito político, judicial ou econômico, é importante considerar os acordos informais e os valores morais, que condicionam a maneira dos indivíduos representarem a realidade e a sua complexidade. Ou seja, a complexidade encontra-se exatamente na falta de formalização na qual os agentes da mudança institucional se relacionam. Dessa forma, o autor ainda afirma que as regras formais possibilitam e possuem mecanismos de coordenação. Esses mecanismos podem ser contratos, hierarquias, constituições, sistemas legais e outros itens que tornam os grupos bem-sucedidos.

Dessa forma, percebe-se, segundo Farias, que "as instituições não são apenas regras, mas também sistemas de estímulos à interação; interação essa que se processa sob formas distintas" (2010, p. 94). Ou seja, não apenas as regras devem ser consideradas, mas a interação entre instituições e organizações são importantes, 
bem como determinados valores morais. Assim, é importante considerar a influência do ambiente institucional sobre os elos da cadeia.

\section{Método}

O estudo visou identificar quais são os componentes da cadeia de criação e comercialização dos cavalos crioulos no Rio Grande do Sul e como os elos da cadeia se relacionam, bem como analisar o ambiente institucional desse mercado. Para isso, o presente estudo se baseou em um referencial analítico que aliou a análise de cadeias agrárias e das instituições que delas participam, que contribuem para sua formação específica e o seu desempenho, através de estímulos e barreiras institucionais presentes no interior das cadeias produtivas, no caso, de criação e de comercialização. Para realização da pesquisa, foi utilizada abordagem qualitativa de caráter exploratório.

Dessa forma, foram utilizadas técnicas qualitativas para exploração, privilegiando as análises documentais, o levantamento bibliográfico, a análise de dados secundários e as entrevistas individuais em profundidade realizadas com especialistas e com atores da cadeia em estudo, incluindo representantes do ambiente institucional. É importante ressaltar que a opção pelos dados secundários e pelas entrevistas em profundidade se deu em virtude de haver poucos estudos realizados nesta área.

Para as entrevistas em profundidade, foi realizado um roteiro de entrevista, o qual iniciou com algumas questões específicas e depois seguiu o curso de pensamento do participante com investigações do entrevistador, ou seja, uma entrevista semiestruturada (COOPER, 2011). Os sujeitos da pesquisa que forneceram as informações necessárias para a análise qualitativa foram proprietários de cabanhas, um representante da $\mathrm{ABCCC}$, que também é veterinário, e proprietários de cavalos crioulos. As entrevistas foram realizadas no estado do Rio Grande do Sul, na capital do estado, Porto Alegre, e em cidades da região metropolitana, no período de Janeiro a Março de 2013. Foram realizadas quatro entrevistas em profundidade, e sua amostra foi selecionada por conveniência. Para o levantamento dos dados foram selecionadas cabanhas de três municípios distintos, sendo essas localizadas em Porto Alegre/RS, Guaíba/RS e Eldorado do Sul/RS. Já a ABCCC possui sede em Pelotas/RS e seu representante possui Cabanha com a família em Santa Vitória do Palmar/RS.

As entrevistas em profundidade contemplaram aspectos como as etapas da criação do cavalo crioulo até a sua comercialização, os principais riscos durantes 
as etapas citadas, percepção sobre o crescimento do mercado nacional e internacional e se essa expansão influenciou nos processos de criação e de comercialização, competições, marca, principais instituições, organizações de apoio, existência de relações contratuais entre os agentes, principais criadores e questões tecnológicas.

No entanto, compreende-se como limitação da pesquisa, o pequeno número de entrevistados. Para pesquisas futuras, é possível ampliar o número de entrevistados, contudo, para a presente pesquisa, não houve disponibilidade de tempo em função das distâncias.

\section{Cadeia de Criação e Comercialização de Cavalos Crioulos: o mercado e o ambiente institucional}

\subsection{Mercado de Cavalos Crioulos}

O mercado em análise possui uma entidade regulamentadora, a ABCCC. Sua fundação ocorreu em 28 de fevereiro de 1932, na Associação Rural da cidade de Bagé. Contudo, logo após, Pelotas foi escolhida para sediar a ABCCC, onde permanece até hoje. Os principais objetivos, de acordo com seu estatuto, são congregar os criadores de cavalos crioulos, organizar e manter o registro genealógico, estudar, aprofundar e desenvolver todos os assuntos referentes à raça crioula.

O registro genealógico, citado anteriormente, é um dos itens que agrega valor ao animal e que se encaixa no conceito de custos de transação. Para que um cavalo seja registrado como pertencente à raça crioula de forma definitiva, não basta que seus pais sejam crioulos, é necessário que ele tenha diversas características, determinadas pela $\mathrm{ABCCC}$, como estatura, genética, características físicas, entre outros. Além disso, há condições diferentes para éguas, cavalos castrados e garanhões para adquirir seu registro.

Contudo, não é suficiente para ser considerado crioulo possuir as características e não possuir a documentação oficial. Afinal, caso não possua as características necessárias para receber o registro definitivo, continuará sendo da raça crioula, entretanto, possuirá apenas o registro provisório. Quem determina as especificações é a ABCCC e quem avalia são os técnicos autorizados pela entidade. Uma vez que o animal não atinja as especificações na visita, poderá solicitar, posteriormente, uma nova avaliação. Também é importante ressaltar que o cavalo crioulo possuirá 
o registro provisório automaticamente, no momento em que é filho de cavalos que possuam registro definitivo. Entretanto, os cavalos e éguas que não possuírem o registro definitivo, não poderão gerar filhos, de acordo com as normas da ABCCC, sendo que, neste caso, os machos devem ser castrados.

Com isso, é importante considerar a forma como se dá a criação e a comercialização do cavalo crioulo e analisar a estrutura da respectiva cadeia, pois esse é um fator que pode auxiliar na coordenação das organizações e das instituições que a compõe. A comercialização ocorre de diversas formas, seja por leilões, em feiras, diretamente do produtor, entre outros meios. Deve-se considerar ainda que o processo de criação pode influenciar no momento da comercialização, pois permite que se agregue valor ao animal ou não. A importância do mercado de cavalos crioulos não se restringe apenas aos criadores, mas a diversos outros segmentos, gerando, inclusive, muitos empregos diretos e indiretos. Esse fato pode ser confirmado visto que, ao ano, gera cerca de 238 mil empregos no Brasil, segundo dados da Associação Brasileira de Criadores de Cavalos Crioulos (ABCCC, 2013).

De acordo com a ABCCC, o mercado de cavalos crioulos é composto por 16.042 criadores, sendo que 2.880 destes são associados. O número de proprietários supera o valor de criadores, estando em 33.522.

O Stud book da raça, responsável pela organização e conservação da genealogia dos cavalos crioulos, possui o registro de 419.047 animais (352.771 vivos e 66.276 mortos). Esses animais estão distribuídos em cem por cento do território nacional. Também há animais registrados na Argentina, Uruguai, Paraguai e Chile. Os países citados possuem suas associações específicas e há ainda a Federação Internacional de Criadores de Cavalos Crioulos (FICCC), que é responsável por congregar todas as associações existentes. É importante salientar que o Chile, apesar de ser uma potência na criação de cavalos crioulos, de forma quantitativa e qualitativa, está suspenso da Federação, pois se recusou a divulgar seus registros genealógicos, fato que poderia contribuir para o constante desenvolvimento da raça. Além disso, o país não aceitou denominar os seus animais como "Criollo Chileno". De acordo com a ABCCC ([201-?]), determinado posicionamento fechou as portas para a internacionalização com os demais países criadores da raça. A definição da FICCC acarretou ainda a não aceitação de importação de animais e sêmen chilenos, o trancamento do registro genealógico e a não realização de eventos oficiais da Federação no país.

No Brasil, o mercado organiza-se através da ABCCC, que é dividida em núcleos. Atualmente, há 94 entidades (64 no Rio Grande do Sul e 30 entre Santa Catarina, Paraná, São Paulo, Rio de Janeiro, Brasília, Mato Grosso e Mato Grosso do 
Sul). Conforme a $\mathrm{ABCCC}$, o número exato de cavalos crioulos registrados em cada região do Brasil, no primeiro semestre de 2013, é o seguinte:

- Norte: 1.412 Cavalos Crioulos registrados

- Nordeste: 530 Cavalos Crioulos registrados

- Centro-Oeste: 5.945 Cavalos Crioulos registrados

- Sudeste: 11.442 Cavalos Crioulos registrados

- Sul: 332.624 Cavalos Crioulos registrados

O mercado de cavalos crioulos está em um processo de expansão, além da ótica econômica, em quantidade de plantel e em qualidade, de acordo com a ABCCC. A Associação afirma que a importância econômica da raça, no RS e no restante do país, surgiu da sua utilização com o manejo do gado bovino. Historicamente, esse processo era realizado pelos tropeiros, que transportavam o gado do RS para o restante do país. A partir disso, intensificou-se a relevância comercial dos cavalos crioulos.

É importante, ao mesmo tempo, ressaltar a importância econômica do setor, devido ao valor de comercialização que ele gera. Esse fato pode ser identificado uma vez que o valor total comercializado (considerando vendas particulares e remates) em 2013 foi de $\mathrm{R} \$ 183$ milhões, valor que superou em 8,64\% o ano de 2012. Os remates organizados por criadores superaram $\mathrm{R} \$ 7$ milhões, no mesmo ano, valor que supera toda a comercialização do setor em 2000, que totalizou $R \$ 6,54$ milhões (ABCCC, 2014).

Esses valores confirmam os dados obtidos nas entrevistas em profundidade, pois todos os entrevistados concordam que o mercado estudado está em um processo significativo de crescimento. Essa expansão tornou-se mais efetiva na última década, conforme a Figura 2, apresentada a seguir.

De acordo com Mauro Ferreira, atual presidente da Associação,

A raça cresce de uma forma sustentada e firme, mas ainda temos muito mais a crescer. Temos nossa manada concentrada no Sul e ainda temos todo o Brasil para crescer de forma que nossos investimentos são no sentido de expandir a raça para o Centro do país e abrir mercado (ABCCC, 2014).

Dessa forma, é importante considerar que é de extrema importância para ABCCC expandir o mercado de cavalos crioulos de forma maciça para todo país, fato que já está iniciando. Para isso, uma das estratégias utilizadas pela Associação é levar um número maior de provas para fora do estado, incentivando que criadores de outras regiões continuem no mercado e preocupem-se com a evolução do mesmo, de forma quantitativa e qualitativa, ou seja, adquirindo mais animais, 
mas sempre considerando o aperfeiçoamento da raça. Contudo, há também a preocupação de captar novos criadores, e as provas também são uma boa ferramenta para atingir este objetivo.

Figura 2 - Vendas realizadas em leilões entre os anos 2000 e 2013

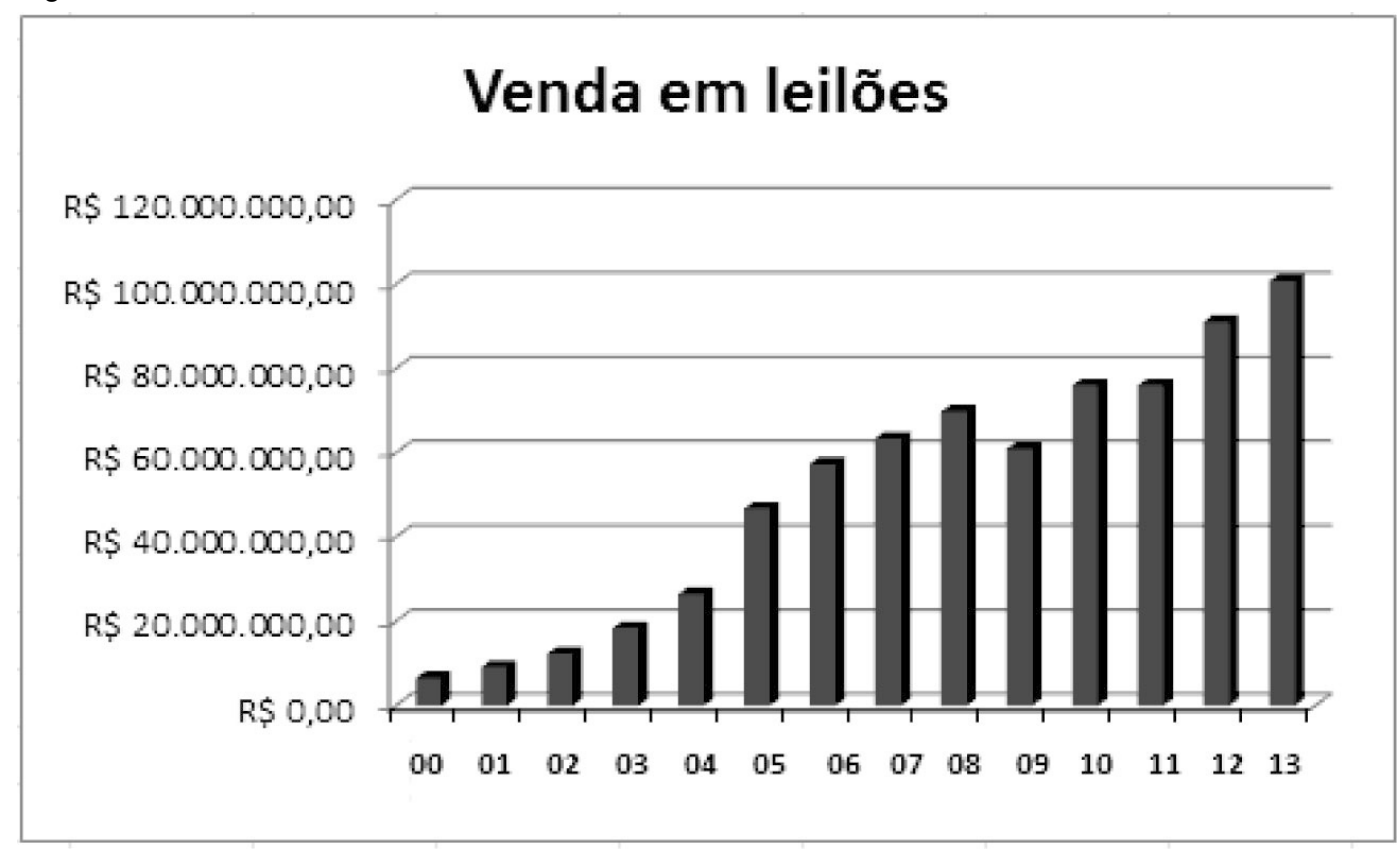

Fonte: dados fornecidos pela ABCCC (2014).

O mercado em análise, uma vez fortalecido, acaba por favorecer outros mercados que estão interligados a ele, e, por este motivo, é essencial estudar a cadeia como um todo. Mercados de insumo, como ração, medicamentos, acessórios, selaria, ferrageamento e outros, estão firmando e aumentando o seu espaço juntamente com o setor de Cavalos Crioulos.

É importante considerar que o cavalo crioulo possui como habitat natural a região do Pampa, compreendida entre o sul do Brasil, a Argentina e o Uruguai, onde a raça desenvolveu-se. Dessa forma, no que tange à alimentação, é essencial que os fornecedores desses insumos preocupem-se com a alimentação adequada às necessidades dos animais, que essa seja equilibrada, para que se possa manter o máximo da sua capacidade (CIRNE, 2013). Caso o animal saia de sua região natural, deve ter, pois, as condições adequadas garantidas em qualquer localidade, sendo essencial a especialização de insumos para atender essa raça. 
Assim como a alimentação, os medicamentos também são essenciais para o bom desenvolvimento da raça e, principalmente, para o bem estar animal. Selarias e ferrageamento também são setores que crescem com a no mercado e podem ser considerados bens complementares. Ou seja, quanto maior a procura por cavalos crioulos e sua utilização, independente do objetivo, maior será a procura por selaria, arreio e ferrageamento. E não apenas maior, como só irão ser consumidos em decorrência da criação de cavalos. Consequentemente, quanto mais expressiva for à criação e à comercialização de cavalos crioulos, mais beneficiados serão os mercados relacionados, inclusive com o aumento de empregos diretos e indiretos. Os setores de moda e publicações especializadas também são beneficiados com o crescimento do mercado de cavalos crioulos.

Entretanto, apesar do significativo crescimento do mercado e de sua participação na economia do estado, são poucas cabanhas e poucos criadores que realmente contribuem para esse aumento significativo, uma vez que são poucas as grandes cabanhas que podem investir alto em genética e aperfeiçoamento.

\subsection{Aspectos relevantes do ambiente institucional}

Nas entrevistas que serviram de suporte às análises desse estudo, foram considerados diversos aspectos inerentes à criação e à comercialização de cavalos crioulos no RS. Entre eles, podem ser citados a marca, os riscos que existem no processo, a organização da criação e da comercialização e o ambiente institucional, compreendido pelas questões genéticas, regulamentações do mercado etc, que serão abordados com maior profundidade na sequência.

\section{a) Marca da Cabanha}

No mercado de cavalos crioulos a marca da cabanha é essencial para agregar valor ao animal e para garantir um bom desempenho da organização que o produz em seu mercado de atuação. Além disso, a marca garante ao comprador segurança e credibilidade, uma vez que, quando se adquire um animal, não há muitas garantias de que ele vá atender aos anseios de quem o comprou, pois é possível conhecer o comportamento e a qualidade do animal apenas após um período de convivência com este.

Contudo, quando a marca da empresa que vende esse animal é consolidada no mercado, garante ao comprador maiores chances de ter adquirido um animal de boa genética e saúde e que atenda ao que se espera dele. Segundo pesquisa 
realizada pelo grupo Equonomia da Esalq/USP (PESQUISA, 2014) (Escola Superior de Agricultura Luiz Queiroz), é importante ressaltar que o cavalo crioulo pode ser comprado por diferentes motivos, sendo os principais deles:

$\rightarrow$ Esporte

$\rightarrow$ Lazer

$\rightarrow$ Trabalho

Ainda, de acordo com a pesquisa, o esporte é o motivo que mais atrai os compradores, e isso se deve ao aumento da importância que as provas e as competições estão ganhando no RS e também no restante do país. Esse aspecto será abordado com mais profundidade posteriormente.

Outro aspecto atrelado à marca é a questão genética, que possui alto valor para os cavalos crioulos. Há algumas Cabanhas que possuem sua marca consolidada no mercado por fornecer de forma contínua animais de alta qualidade genética ao mercado. Afinal, quando se adquire um animal com qualidade genética reconhecida, aumentam-se as chances de que ele vá atender determinadas expectativas funcionais e de personalidade, ou de que vá gerar animais de alta qualidade. De certa forma, a genética e a marca da cabanha atuam como redutores da incerteza do processo de comercialização de cavalos crioulos.

Os criadores que ofertam ao mercado animais de alta qualidade genética acabam agregando valor e criando uma relação de confiança perante o público consumidor, favorecendo sua participação no mercado e desenvolvendo vantagens competitivas. Em contraponto, muitos produtores que ainda não possuem efetiva participação no mercado possuem animais de alta qualidade genética, mas não agregam tanto valor ao animal por não possuírem uma marca consolidada.

O porte das cabanhas e as dificuldades de financiamento das operações de criação e comercialização são barreiras ao crescimento da cadeia. Muitas das pequenas cabanhas existentes do RS não adquirem seus animais com performance comprovadas nas pistas (de provas e de competições). Segundo Silva, os proprietários de pequenas cabanhas "utilizam a intuição e a sorte, e quase sempre esse processo dá errado" (2014, p. 43). Isso afeta o seu posicionamento no mercado. $\mathrm{E}$ a ausência de uma marca consolidada afeta os preços de comercialização dos animais. 


\section{b) Comercialização e riscos}

O processo de comercialização no mercado de cavalos crioulos não é padronizado, pois depende, principalmente, de quem realiza a venda. Normalmente, quando a venda é realizada por pequenos produtores, ela é feita diretamente pelo proprietário. Nesse processo, o comprador procura a cabanha ou o criador e realiza a compra. Por este motivo, são raras as transações que acompanham relações contratuais formais, prevalecendo as informais, visto que os agentes normalmente já são conhecidos e a há confiança entre eles.

Ainda conforme abordado anteriormente, é importante considerar a questão da marca no processo de comercialização, pois, por maior qualidade que possua 0 animal, se o vendedor não possui uma marca consolidada no mercado, as vendas permanecem sendo realizadas, em geral, diretamente com o produtor, dificilmente sendo vendidos em grandes leilões. Além disso, o valor de venda é menor quando é vendido por um pequeno produtor do que quando é vendido por uma organização que possua reconhecimento no mercado.

No que diz respeito a grandes produtores, a comercialização, geralmente, é realizada por leilões. Este processo possibilita a venda de uma maior quantidade de animais e um maior alcance geográfico, uma vez que não só é realizado presencialmente, mas também transmitido por canais televisivos ou pela internet, podendo ser comprado por criadores de qualquer local do país. Neste sistema de comercialização, são vendidos animais de maior valor, em condições de venda facilitadas, por exemplo, parcelado em cinquenta vezes na maioria dos casos. Contudo, é nesse aspecto que os entrevistados identificam o maior gargalo do setor: a inadimplência.

À luz da NEI, Azevedo (2000, p. 36), afirma que "coleta de informações, salvaguardas contratuais e utilização do sistema judiciário são custos incorridos para se evitar prejuízos decorrentes da ação oportunista dos demais agentes. Todos esses custos são custos de transação". Com isso, devem-se considerar os riscos atrelados à comercialização. Os riscos, em geral, podem ser barreiras que dificultam ou impedem o alcance de um objetivo. Durante o levantamento de dados, realizou-se a divisão de riscos em dois processos separados, sendo eles os riscos relacionados à criação e os riscos relacionados à comercialização.

No caso da comercialização, destaca-se a inadimplência. Com a expansão do mercado, a comercialização através de leilões e remates (em geral transmitidos pela televisão e/ou pela internet), acaba atingindo uma maior extensão geográfica. Com isso, tem aumentado o número de aquisições de animais em estados, principalmente, do centro do país. Porém, as vendas são realizadas com pagamento 
facilitado, na maior parte dos casos, ocorrendo com frequência o pagamento apenas das parcelas iniciais. Como a busca e a apreensão dos animais se caracteriza por um processo demorado e caro, essa medida não é aplicada, gerando um índice alto de inadimplência na comercialização dos cavalos crioulos, e esse fator está sendo visto como preocupante para os criadores. Eles, inclusive, ressaltam que, na venda conhecida como venda de porteira, na qual os animais são comprados diretamente nos criatórios os compradores são próximos e normalmente conhecidos no meio, há maior índice de pagamento e quitação dos animais.

Os riscos atrelados à criação dos animais estão vinculados à possibilidade de 0 animal não nascer com os aspectos genéticos esperados, ainda que passe por uma excelente combinação genética e funcional de seus antecessores; ainda há os riscos de doenças e machucados, que podem ser minimizados, mas sempre vão existir. Afinal, é comum a lesão em cercas e o desenvolvimento de doenças, como a cólica equina. Para minimizar esses riscos um bom planejamento e acompanhamento veterinário são essenciais, além da necessidade de proporcionar aos animais manejo e ambiente adequado. Contudo, não é possível eliminar totalmente os riscos, pois muitos deles não possuem controle humano, diferentemente das questões relacionadas à comercialização.

Dessa forma, pode-se considerar que os principais riscos atrelados à cadeia são naturais, como doenças e questões genéticas, quando o cruzamento entre animais não corresponder ao esperado, e acidentes no ambiente onde o cavalo vive ou onde ocorrem treinos e preparação para provas. São riscos também a inadimplência, que tem se tornado a principal preocupação dos criadores que optam pela comercialização através de remates e de leilões.

\section{c) Provas e premiações}

Outro aspecto importante são as provas e os campeonatos que envolvem os cavalos crioulos. Há diversos tipos de competições, desde competições simples e frequentes, que abrangem uma maior diversificação de animais competidores em provas de tiro de laço, realizadas, em sua maior parte, em rodeios, até competições de alto nível, como o Freio de Ouro.

De acordo com a ABCCC, o Freio de Ouro proporcionou que a raça chamasse atenção da mídia: programas de televisão exclusivos, revistas e sites especializados e específicos da raça. Com isso, é possível considerar o Freio de Ouro um divisor de águas do mercado da raça, que proporcionou ainda mais preocupação e qualidade no desenvolvimento da mesma. 
Para as competições como Freio de Ouro, nas quais uma conquista agrega um valor significativo ao animal e a seu genitor, é necessário possuir cavalos muito bons genetica, morfologica e funcionalmente. São diversas etapas para que um cavalo crioulo chegue à fase final da competição, garantindo sua valorização pela participação. Entretanto, para que os animais cheguem ao nível dessa competição é necessário alto investimento por parte do criador, e suporte de outros profissionais para garantir que o cavalo alcance os resultados esperados na competição. Entre esses profissionais, podemos considerar os ginetes e os treinadores, também bons veterinários e bons manejadores.

A alimentação dos animais deve ser especial, assim como precisam estar preparados física, morfológica e funcionalmente. Dessa forma, o alto investimento vai gerar um alto retorno, caso o animal se classifique para a competição, retorno que cresce à medida que ele ocupa as três primeiras posições.

Vale considerar que um animal pode agregar valor mesmo sem ter conquistado nenhum título, uma vez que seus filhos os conquistem. Isso é controlado pela ABCCC através do Registro de Méritos, no qual o animal vai soma pontos mesmo que não participe de nenhuma competição, porque acumula as conquistas de seus filhos.

\section{d) Regulação do mercado}

De acordo com Azevedo:

[...] a criação de regras que disciplinam o comportamento dos participantes de um sistema agroindustrial pode ser decisiva para sua eficiência e competitividade, ao permitir uma coordenação de suas ações mais apurada do que aquela que seria obtida por meio do uso da coordenação via sistema de preços $(2000$, p. 34$)$.

Isso significa que nem sempre são os preços que vão determinar o funcionamento de um mercado, e sim as instituições. A partir disso, pode-se considerar que o principal órgão regulador do mercado de Cavalos Crioulos é a ABCCC. A organização é responsável pelo apoio e pelo desenvolvimento não apenas da raça, mas também da cadeia como um todo.

De acordo com seu estatuto, entre suas principais atribuições, considera-se responsável por organizar o mercado e os registros genealógicos da Raça Crioula e os seus regulamentos; estimular e fomentar, por todos os meios ao seu alcance, a criação intensiva e extensiva de equinos da Raça Crioula, procurando sua padronização através da difusão e do emprego dos mais modernos métodos de seleção; 
organizar anualmente, além das "Exposições Oficiais de Equinos Crioulos", campeonatos, certames, torneios, marchas de resistência ou outras quaisquer iniciativas que visem manter sempre forte o elo entre os criadores da raça, dentro de um salutar sistema de competições zootécnicas ou funcionais; estudar, aprofundar e desenvolver todos os assuntos referentes à Raça Crioula, ao que consagrará todos os recursos aconselháveis e de que possa dispor; promover entendimentos, acordos e convênios com os governos Federal, Estaduais e Municipais, para a execução de atividades relativas ao fomento e defesa da exploração da Raça Crioula.

Assim, com base nessas atribuições regimentais, percebe-se o importante papel que cumpre a ABCCC na criação e na consolidação da cadeia. Ainda que sua atuação esteja focada nos aspectos relacionados à criação, muitas atividades suas têm reflexos sobre a comercialização.

\section{Análise da estrutura da cadeia}

Inicialmente, é importante elencar quem são os principais componentes dessa cadeia. Dessa forma, é possível realizar uma pré-divisão entre os componentes relacionados à criação e à comercialização e os componentes que servem como grupo de apoio aos processos citados anteriormente.

No que tange à criação de cavalos crioulos, os principais agentes são as cabanhas, os proprietários, os empresários, as fazendas e outras organizações que, de fato, criam os animais. Há diversas formas de criar um cavalo crioulo, porém, de modo geral, as principais são:

- Individual - proprietários e empresários;

- Cabanhas - criatórios especializados em Cavalos Crioulos;

- Fazendas - que mesclam a criação dos Cavalos Crioulos com outras culturas.

É importante considerar ainda as parcerias, principalmente quando o animal possui alto valor comercial e agregado. Nesses casos, é comum a formação de condomínios, ou seja, diversos agentes se unem para adquirir um animal ou parte dele. Esse processo é acordado e garantido através de relações contratuais, devido ao alto valor envolvido na transação.

Com relação à comercialização, os envolvidos podem ser os próprios agentes que criam os animais, no processo denominado como "comercialização de porteira", ou seja, o interessado procura o proprietário/criador do animal diretamente, na propriedade ou em pequenos leilões e feiras. Esse tipo de comercialização, como citado anteriormente, é mais comumente aplicado a pequenos e médios criadores.

Teoria e Evidência Econômica - Ano 23, n. 48, p. 63-91, jan./jun. 2017 
Além disso, a comercialização pode ser realizada por leiloeiros especializados, que atingem grande extensão geográfica. Esses leilões podem ser realizados de forma presencial, televisivos, virtuais ou mesclando essas três formas.

Essas são as principais e mais comuns práticas de comercialização, e, conforme citado, os principais agentes envolvidos são:

- Criadores/Proprietários;

- Leiloeiras.

Podem-se considerar como componentes de apoio todos os agentes que prestam serviços e auxiliam para que o processo de criação e comercialização seja possível. Os principais componentes são:

- Veterinários;

- Fornecedores de insumos - Alimentação, medicamentos e acessórios;

- Fornecedores de arreios - Selas, freios e outros;

- Domadores e treinadores;

- ABCCC - Associação Brasileira de Criadores de Cavalos Crioulos.

É importante avaliar que todos os agentes de apoio podem contribuir tanto nos processos de criação, quanto nos processos de comercialização, relacionando-se com diversos componentes e em diferentes momentos.

O processo de criação inicia-se no momento da escolha genética que o cavalo crioulo vai possuir, a partir da escolha dos pais que serão colocados em cruzamento. Após o processo de escolha, espera-se o momento fértil da égua para que ele ocorra. Contudo, é necessário ainda que a égua aceite o garanhão escolhido para a efetivação do cruzamento. Em caso de aprovação, ocorre a monta e a provável fecundação do óvulo, pois ela nem sempre ocorre com sucesso. Ocorrida à fecundação, a gestação da égua dura um período de onze meses. Após o nascimento do potro, há o importante processo de amamentação, que acontece em um período de aproximadamente seis meses e é essencial para o bom desenvolvimento do cavalo. O próximo passo na criação é a doma que pode ser dividida em duas etapas: a doma de baixo e a doma de cima. A doma de baixo tem o objetivo acostumar o cavalo ao manejo, tanto diário quanto voltado para a apresentação em determinadas avaliações morfológicas. Já a doma de cima inicia-se quando o animal está fisica e psicologicamente pronto, em torno de seus 36 meses, e vai estar voltada para os objetivos que o cavalo vai possuir, ou seja, se será utilizado para lazer, trabalho, competições, entre outros. Assim que o cavalo estiver devidamente domado, inicia-se o seu treinamento, que varia caso o cavalo seja preparado para provas e competições

Teoria e Evidência Econômica - Ano 23, n. 48, p. 63-91, jan./jun. 2017 
(por exemplo, esportivas) ou seja utilizado para trabalho ou lazer, sua duração vai depender também desses objetivos, podendo ser um processo contínuo.

Após a preparação do animal, o criador vai optar pela comercialização ou não do seu cavalo. Caso decida pela primeira, vai ainda definir qual o método: se através de leilão ou se diretamente na propriedade. É importante ainda considerar que a comercialização pode ocorrer antes da preparação do animal, logo após o desmame ou, então, quando a égua é vendida com o potro ao pé, ou seja, com o potro ainda em processo de amamentação. $O$ processo de comercialização vai depender da definição do criador e da forma com que conduz o seu empreendimento.

A partir da decisão de comercializar e da efetivação da venda, são definidas as relações contratuais (formais ou informais), ou seja, de que forma será entregue o animal, de que forma será realizado o pagamento, entre outras combinações que forem convenientes ao processo. Em seguida, é realizada a entrega do animal, conforme combinado, e efetua-se o pagamento, também conforme combinado no momento da venda.

Com relação à determinação do valor de comercialização, é importante considerar, conforme informado na entrevista pelo representante da ABCCC, que não existe pauta para determinação desse valor, uma vez que esse processo está atrelado aos resultados obtidos pelo animal, tanto no aspecto funcional ou morfológico, bem como nos aspectos genéticos ou relacionados aos resultados obtidos pelos seus filhos através do Registro de Mérito.

O novo proprietário iniciará um novo processo de criação, colocando o animal em cria ou, no caso de um animal castrado, treinando-o ou apenas fazendo a manutenção de seu manejo. Os principais agentes de apoio identificados na pesquisa foram: veterinários, fornecedores de insumos (alimentos, medicamentos e acessórios), fornecedores de arreios (selas, freios e outros), domadores e treinadores, funcionários responsáveis pelo manejo diário, profissionais responsáveis por questões genéticas, a ABCCC (Associação Brasileira de Criadores de Cavalos Crioulos), entre outros. 
Figura 3 - Ambiente Organizacional e Institucional da Cadeia de Criação e Comercialização dos Cavalos Crioulos no RS

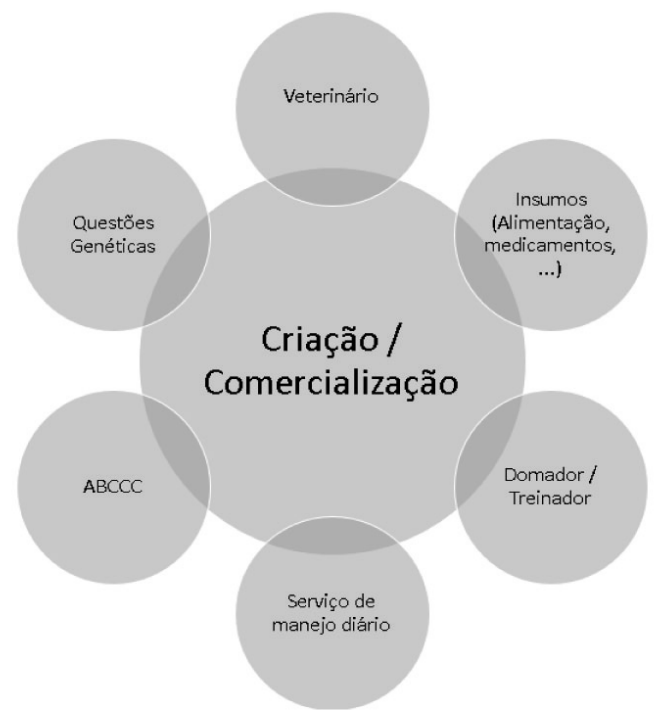

Fonte: elaborada pelos autores.

Esses agentes relacionam-se a todo o momento no processo de criação e comercialização, formando um ambiente organizacional e institucional do qual a cadeia depende para que seja efetiva e alcance os seus objetivos, que são criar com qualidade o cavalo crioulo, favorecendo o setor e a sua economia.

A imagem abaixo representa algumas possíveis relações entre os agentes da cadeia.

Figura 4 - Relação entre os agentes da cadeia

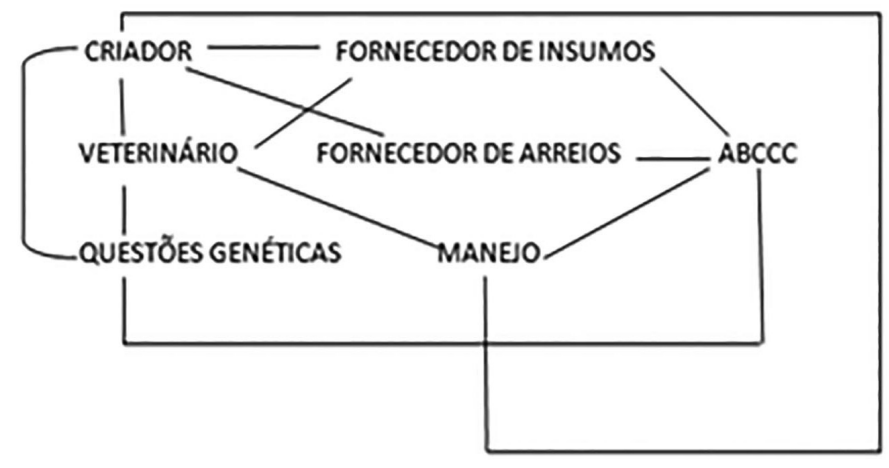

Fonte: elaborada pelos autores. 
Identifica-se, após análise do esquema, que a cadeia não está fundamentada em relações bilaterais, mas multilaterais, pois os agentes se relacionam com diversos outros agentes. Mesmo que esses não possuam relação contratual, em algum momento, as questões institucionais irão impactar no seu funcionamento ou na sua organização.

Pode-se considerar como aspectos institucionais as questões relacionadas à tradição que o cavalo crioulo possui no RS e à sua importância cultural, ao funcionamento e às regulamentações da $\mathrm{ABCCC}$, incluindo as questões genéticas, de que depende o manejo adequado para o melhor desenvolvimento da raça. Igualmente, os aspectos relacionados à confiança entre os agentes, sobretudo no processo de comercialização, apresentam-se como importantes elementos institucionais que devem ser considerados.

\section{Considerações finais}

O presente artigo pretendeu analisar o funcionamento e a organização da cadeia de criação e de comercialização dos cavalos crioulos no RS, bem como a relação entre os elos da cadeia. A importância do trabalho deve-se aos poucos estudos realizados na área e ao crescimento econômico do setor, sendo necessário compreender sua sistemática, que visa ao aumento da eficiência e da eficácia do mercado em análise.

$\mathrm{O}$ artigo apresenta uma definição dos componentes da cadeia. Determinou-se que os componentes são os seguintes: os criadores; os proprietários; as leiloeiras; os treinadores e os domadores; os veterinários; os fornecedores de insumos (alimentos, medicamentos e acessórios); profissionais que realizam o ferrageamento; fornecedores de arreios (selas, freios e outros); a ABCCC (Associação Brasileira de Criadores de Cavalos Crioulos).

Em consideração aos aspectos teóricos da NEI, podem-se considerar algumas restrições formais ao desenvolvimento da cadeia: o estatuto da $\mathrm{ABCCC}$, que define o funcionamento do setor; bem como outros regulamentos desenvolvidos pela entidade, entre eles: os regulamentos de Provas e Competições, o regulamento de Registro Genealógico, o Manual do Criador, os Regimentos Eleitorais, entre outros, que definem as normas que devem ser seguidas pelos criadores da raça e, por conseguinte, como o mercado irá operar. Já as restrições informais seriam aquelas que relacionam o papel da raça à cultura e à tradição gaúcha. Afinal, o cavalo crioulo é um animal símbolo para o povo gaúcho, porque o desenvolvimento desse povo está intrinsicamente relacionado com a presença da raça. $O$ respeito que o animal possui é relevante, e as questões históricas determinam, inclusive, como é realizado o

Teoria e Evidência Econômica - Ano 23, n. 48, p. 63-91, jan./jun. 2017 
treinamento, a doma, quais os trabalhos de lida campeira que desenvolvem e quais os aspectos morfológicos e funcionais devem possuir para que estejam no caminho do desenvolvimento da raça.

Dado o crescimento do segmento, sobretudo nos últimos anos, vislumbra-se um aumento da regulação exercida sobre os criadores e agentes de comercialização. Esse papel, segundo as informações obtidas nas entrevistas, será exercido pela ABCCC, não apenas em nível regional, considerando a região sul do Brasil, mas também em nível nacional. Uma das questões que mais preocupa os agentes, no que tange à regulamentação, diz respeito ao financiamento e à garantia de pagamentos, nos casos de vendas a prazo nos leilões. Na atualidade, esse tema ainda não foi devidamente resolvido, o que impacta nos preços finais dos animais leiloados, uma vez que a incerteza nessas operações ainda é grande.

Pode-se perceber que a adoção da abordagem de cadeia é apropriada para a análise do segmento de cavalos crioulos, porque, como ficou demonstrado, a criação e a comercialização desses animais dependem de uma gama de agentes interligados, e a presença (ou ausência) deles pode determinar o quão eficiente é a cadeia em uma dada região. Aspectos ligados à comunicação e ao aprendizado entre os agentes, aparentemente, carecem de ser mais bem desenvolvidos, a fim de que se tenha um desempenho mais eficiente.

Fica como sugestão para pesquisas futuras a continuidade do estudo, que pode ampliar o número de amostras, para aprofundamento das análises. Ainda podem-se considerar as questões referentes ao processo de internacionalização da cadeia, visando identificar se há alteração em sua organização e em seu funcionamento, se há outros aspectos institucionais que interferem nos seus processos. Há também a possibilidade de realizar estudos individuais sobre cada elo da cadeia e sua relação com o mercado de cavalos crioulos. 


\title{
Chain of creation and commercialization of the Crioulo Horse in Rio Grande do Sul
}

\begin{abstract}
This work aims to analyze the chain of creation and marketing of Criollo Horse in Rio Grande do Sul, in view of its economic importance and because it is a traditional productive activity in the state, participating, even the imagination of the pampas region. The research is based on the study of the Agroindustrial Systems, the coordination and Chains Structuring, in light of the New Institutional Economics. Data collection was conducted through document analysis, secondary data analysis and in-depth interviews with chain actors, characterizing an exploratory study of qualitative approach. A historical analysis of the Criolo Horse market was carried out and a proposal was presented on the structure of the analyzed chain, its links (chain agents) and how they relate.
\end{abstract}

Keywords: Agribusiness Systems. Coordination and Structuring Chains. Crioulo Horses. New Institutional Economics.

\section{La cadena de la creación y comercialización de Caballo Criollo en Rio Grande do Sul}

\section{Resumen}

Este trabajo tiene como objetivo analizar la cadena de la creación y comercialización de caballo criollo en Rio Grande do Sul, en vista de su importancia económica y porque es una actividad tradicional productiva en el estado, participando, incluso la imaginación de la región pampeana. La investigación se basa en el estudio de los sistemas agroindustriales, la coordinación y estructuración Cadenas, a la luz de la Nueva Economía Institucional. La recolección de datos se realizó mediante el análisis de documentos, análisis de datos secundarios y entrevistas en profundidad con actores de la cadena, la caracterización de un estudio exploratorio de abordaje cualitativo. Se realizó un análisis histórico del mercado de caballos Criollo y presentó una propuesta de estructura de la cadena, sus enlaces (agentes de la cadena) y cómo se relacionan.

Palabras clave: Caballo Criollo. Coordinación y estructuración de Cadenas. Nueva Economía institucional. Sistemas Agroindustriales. 


\section{Referências}

AGUILAR FILHO, H. A. de. O institucionalismo de Douglass North e as interpretações Weberianas do atraso brasileiro. 2009. Tese (Doutorado em Economia) - Programa de Pós-Graduação em Economia, Faculdade de Ciências Econômicas, Universidade Federal do Rio Grande do Sul, Porto Alegre, 2009.

AREND, M.; CARIO, S. A. F.; ENDERLE, R. A. Instituições, inovações e desenvolvimento econômico. Pesquisa \& Debate, São Paulo, v. 23, n. 1 (41), p. 110-133, 2012.

ASSOCIAÇÃO BRASILEIRA DE CRIADORES DE CAVALOS CRIOULOS. Estatuto da Associação Brasileira de Criadores de Cavalos Crioulos. Rio Grande do Sul, 2011. Disponível em: <http:// www.racacrioula.com.br/site/content/entidade/estatuto.pdf>. Acesso em: 15 set. 2013.

Cavalo Crioulo vira mercado que move $R \$ 1,28$ bilhão por ano. 16 ago. 2013. Disponível em: <http://zerohora.clicrbs.com.br/rs/economia/campo-e-lavoura/noticia/2013/08/cavalo-crioulo-vira-mercado-que-move-r-1-28-bilhao-por-ano-4236327.html>. Acesso em: 29 set. 2013.

História do Cavalo Crioulo. [201-?]. Disponível em: <http://www.racacrioula.com.br/site/ content/noticias/detalheNoticias.php?id=8834> . Acesso em: 16 ago. 2017.

AZEVEDO, P. F. Nova economia institucional: referencial geral e aplicações para a agricultura. Agricultura em São Paulo, São Paulo, v. 47, n. 1, p. 33-52, 2000.

BEGNIS, H. S. M.; ESTIVALETE, V. de F. B; PEDROZO, E. A. Confiança, comportamento oportunista e quebra de contratos na cadeia produtiva do fumo no sul do Brasil. Gestão e Produção, São Carlos, v. 14, n. 2, p. 311-322, mai./ago. 2007.

CIRNE, M. Nutrição equilibrada de Norte a Sul. ABCCC, 23 maio 2013. Disponível em: <http:// portal.racacrioula.com.br/site/content/noticias/detalheNoticias.php?id=11253>. Acesso em: 6 jun. 2014.

CONCEIÇÃO, O. A. C. O conceito de instituição nas modernas abordagens institucionalistas. Revista de economia contemporânea, Rio de Janeiro, v. 6, n. 2, p. 119-146, jul./dez. 2002.

DIAS, R. R. Um modelo de formação e organização de cadeias de agronegócios. 2000. 127 f. Dissertação (Mestrado em Agronegócio) - Programa de Pós-Graduação em Agronegócios, Centro de Estudos e Pesquisas em Agronegócio, Universidade Federal do Rio Grande do Sul, Porto Alegre, 2000.

FARIAS, C. V. S. Aprendizado, Inovação e Cooperação: um estudo do segmento vinícola do arranjo produtivo da vitivinicultura da Serra Gaúcha. Dissertação (Mestrado em Economia) - Programa de Pós-Graduação em Economia, Universidade do Vale do Rio dos Sinos, São Leopoldo, 2010. $198 \mathrm{f}$.

FARINA, E. M. M. Q. Competitividade e coordenação de sistemas Agroindustriais: um ensaio conceitual. Revista Gestão \& Produção, São Paulo, v. 6, n. 3, p. 147-161, dez. 1999.

FIANI, R. "Teoria dos custos de transação". In: KUPFER, D.; HASENCLEVER, L. (Org.). Economia Industrial: Fundamentos Teóricos e Práticas no Brasil. Rio de Janeiro: Elsevier, 2002. p. 273-281.

FISCHMANN, A. A. Utilização de indicadores de desempenho como instrumentos de suporte à gestão estratégica. In: ENCONTRO DA ANPAD, 23, 1999, Anais... Foz de Iguaçu: Enanpad, 1999. v. 1. p. 1-14.

Teoria e Evidência Econômica - Ano 23, n. 48, p. 63-91, jan./jun. 2017 
GALA, P. A teoria institucional de Douglass North. Revista de economia política, São Paulo, v. 23, n. 2, (90), p. 89-105, abr./jun. 2003.

LONGHI, E. H.; MEDEIROS, J. X. Importância da coordenação nas cadeias produtivas: caso do programa de fruticultura do oeste goiano. Revista Economia e Sociologia Rural, Brasília, v. 41, n. 3, p. 73-94, 2003. Disponível em: <http://www.scielo.br/pdf/resr/v41n3/a04v41n3.pdf>. Acesso em: 13 out. 2013.

NORTH, D. C. Economic performance through time. The American economic review, St. Louis, v. 84, n. 3, p. 359-368, jun. 1994.

SAAB, M. S.; NEVES, M. F.; CLAUDIO, L. G. O desafio da coordenação e seus impactos sobre a competitividade de cadeias e sistemas agroindustriais. Revista Brasileira de Zootecnia, Viçosa, v. 38, p. 412-422, jul. 2009. Disponível em: <http://www.scielo.br/scielo.php?script=sci_arttext\&pi$\mathrm{d}=\mathrm{S} 1516-35982009001300041 \& \mathrm{lng}=\mathrm{pt \& nrm=iso>}$. Acesso em: 12 out. 2013.

ZYLBERSZTAJN, D. Estruturas de Governança e Coordenação do Agribusiness: Uma Aplicação da Nova Economia das Instituições. 1995, 241 f. Tese (Doutorado em Administração) - Faculdade de Economia, Administração e Contabilidade, Departamento de Administração, Universidade Federal de São Paulo, São Paulo, 1995.

"Conceitos Gerais, Evolução e Apresentação do Sistema Agroindustrial". In:

NEVES, M. F. (Org.). Economia e gestão de negócios agroalimentares: indústria de alimentos, indústria de insumos, produção agropecuária, distribuição. São Paulo: Pioneira, 2000. p. 1-21. 